\title{
Robust optimization for volume variation in timber processing
}

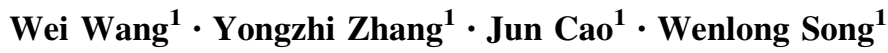

Received: 30 July 2015/ Accepted: 25 March 2016/Published online: 20 May 2017

(c) The Author(s) 2017. This article is an open access publication

\begin{abstract}
Volume variation is an uncertainty element which affects timber processing. We studied the volume variation of logs caused by quality defects in traditional timber processing and set up an optimization approach, using a robust optimization method. We used total number of acceptable boards produced to study the relationship between board thickness and raw material $\log$, using a heuristic search algorithm to control the variation of board volume to improve the output of boards, reduce the quantity of by-products, and lower production costs. The robust optimization method can effectively control the impact of volume variations in timber processing, reduce cutting waste as far as possible using incremental processing and increase profits, maximize the utilization ratio of timber, prevent waste in processing, cultivate the productive type of tree species and save forest resources.
\end{abstract}

Project funding: This study was supported by the Fundamental Research Funds for the Central Universities (Project No. 2572015CB06) and Nature Science Foundation of Heilongjiang Province (LC201407).

The online version is available at http://www.springerlink.com

Corresponding editor: Yu Lei.

Wei Wang

cedar3@163.com

1 Northeast Forestry University, Harbin 150040, People's Republic of China
Keywords Timber mill $\cdot$ Volume variation $\cdot$ Heuristic search algorithm $\cdot$ Robust optimization

\section{Introduction}

With the implementation of state-owned forest reform, all the key state-owned forest areas in Heilongiiang province are closed to commercial harvesting, so forest enterprises must use available resources. The utilizable forest resource in production is limited. The natural growth of the raw material, timber logs, varies considerably over long growth periods. As the demand for wood products increases, timber mills must improve the utilization of $\operatorname{logs}$ to meet market needs and develop their business.

Traditional timber processing is not flexible enough, and there is no way to measure and control the variations in the volume of timber in timber processing. This problem lowers the value and volume of lumber output and increases the cost of manufacturing. A robust optimization approach is able to control the effect of variations in volume of timber available, and offers a scientific theory for timber processing.

The robust optimization approach was first applied by Soyster (1973). Further research has been conducted on robust optimization using different approaches (Bertsimas and Sim 2004a, b; Leung and Chan 2009). This methodology has been applied successfully to different types of problems and to uncertainties in forest production (Zanjani et al. 2010; Alvarez and Vera 2014; Varas et al. 2014; Alem and Morabito 2012).

Based on the robust optimization theory, this thesis make a research of production plan and make an optimization for traditional timber processing. The research technical route shown as Fig. 1: 


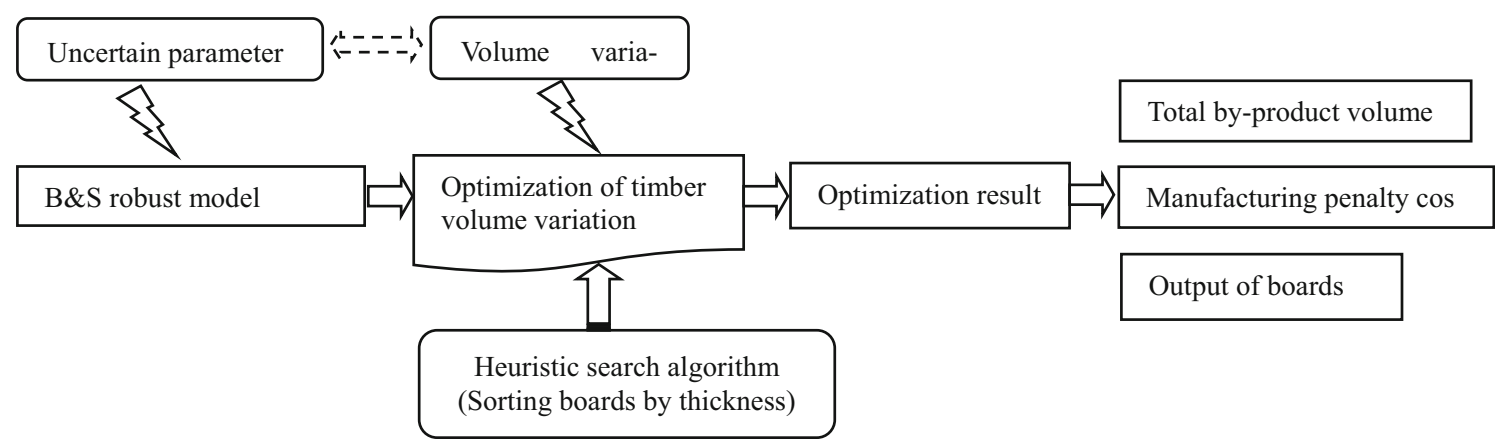

Fig. 1 Research technical route

\section{Materials and methods}

\section{Robust optimization and B\&S (Bertsimas and Sim) robust model}

Robust optimization is a modeling method of manipulating data uncertain (Bental et al. 1999; Ben-Tal and Nemirovski 2000). The purpose of robust optimization is to fulfill the model constraints and to control the data simultaneously. Using robust optimization, the original model related to an uncertainty problem is changed to a semi-infinite robust optimization model using a corresponding formula. The feasible solution and the optimum solution are defined as the robust feasible solution and the robust-optimum solution of the uncertainty problem. The quantitative repeatability of robustness:

$\rho_{\mu}\left(\Phi, \pi_{j}\right)=\underset{\phi_{i} \in \Phi}{\operatorname{Min}}\left(r_{\mu}\left(\phi_{i}, \pi_{j}\right)\right)$

where, $\Phi$ is the assemblage of all performance characteristics, $\phi_{i}$ the $i$ parameter in assemblage $\Phi, \pi_{j}$ the $j$ parameter that effects disturbance of object function, $\mu$ the robust mapping, $r_{\mu}\left(\phi_{i}, \pi_{j}\right)$ the robust radius of mapping $\mu$, when taking $\phi_{i}$ and $\pi_{j}$ into account, and $\rho_{\mu}\left(\Phi, \pi_{j}\right)$ is the robust of mapping $\mu$ when taking $\Phi$ and $\pi_{j}$ into account.

The B\&S robust model advanced by Bertsimas and Sim (Bertsimas and Sim 2003, 2004a, b), comes from linear programming. The assemblage, which is formed from the columns of uncertain parameter $a_{i j}$ in $i$ line of coefficient matrix $A$, is defined as the assemblage $\mathrm{J}_{\mathrm{i}} ; \mathrm{a}_{\mathrm{ij}}$ can be regarded as a symmetrically and limited random variable $\tilde{a}_{i j}$; the definition domain is $\left[\mathrm{a}_{\mathrm{ij}}-\widehat{\mathrm{a}}_{\mathrm{ij}}, \mathrm{a}_{\mathrm{ij}}+\widehat{\mathrm{a}}_{\mathrm{ij}}\right]$, to every bound $\mathrm{i}$, using parameter $\Gamma_{i} \in 0,\left[\left|J_{i}\right|\right]$ to adjust conservative level of solutions. In the B\&S robust model, the minimum whole number is no greater than the uncertain date $a_{i j}$ is changing in interval $\left[a_{i j}-\widehat{a}_{i j}, a_{i j}+\widehat{a}_{i j}\right]$, another coefficient is changing in $\left[a_{i j}-\left(\Gamma_{i}-\Gamma_{i}\right)\left|\widehat{a}_{i j}\right|\right.$, $\left.a_{i j}+\left(\Gamma_{i}-\Gamma_{i}\right)\left|\widehat{a}_{i j}\right|\right]$, and $a_{i j}$ is random in $\left[a_{i j}-\widehat{a}_{i j}, a_{i j}+\widehat{a}_{i j}\right]$. The corresponding formula of robust is:

$$
\sum_{j} a_{i j} x_{j}+\max _{\left\{S_{i} \cup\left\{t_{i}\right\}\left|S_{i} \subseteq J_{i},\right| S_{i} \mid=\Gamma_{i}, t_{i} \in J_{i} ¥ S_{i}\right\}}\left\{\sum_{j \in S_{i}} \widehat{a}_{i j} y_{i}+\left(\Gamma_{i}-\Gamma_{i}\right) \widehat{a}_{i t_{i}} y_{t_{i}}\right\}
$$

When $\Gamma_{i}$ is an integer, the function of $\beta_{i}\left(x, \Gamma_{i}\right)=$ $\underset{\left\{S_{i} \subseteq J_{i},\left|S_{i}\right|=\Gamma_{i}\right\}}{\operatorname{Max}}\left\{\sum_{j \in S} a_{i j}\left|x_{j}\right|\right\}$ is protecting $i$ bound; When $\Gamma_{i}=0, \beta_{i}\left(x, \Gamma_{i}\right)=0$, the $i$ bound transfers to nominal problem. $\Gamma_{i} \in\left[0,\left|J_{i}\right|\right]$ is used to adjust conservative level of the model.

\section{Construction of the volume variation robust optimization model}

\section{Description of problems}

If the quantity of boards in an order is $n$ (use $i=1, \ldots, \mathrm{n}$ ), the thickness of the boards is $u_{i}$; the width of boards is $w_{i}$; then every board must be produced from standard diameter logs on a band saw. Traditional timber processing would use the principle of manufacturing first and then cleaning up. Standard logs $k$ would be produced by a standard cutting scheme $e_{0}$. Defective boards would be discarded after timber processing. Boards produced from the same log are kept to the same thickness to reduce the time needed for band saw adjustment. An adjustment penalty cost is assessed if the thickness must be changed and given the value $c_{k i}^{u} x_{k i}$; the penalty parameter is $\gamma^{u}$. The board thickness should meet the width limit for the boards produced. If the width is more than or less than the width limit, there will be a penalty cost $c_{k i}^{w} x_{k i}$, the penalty parameters are $\gamma_{+}^{w}$ and $\gamma_{-}^{w}$. If the total volume of lumber is less than volume of logs, there will be a volume penalty cost $c_{k i}^{v t} x_{k i}$, the penalty parameter is $\gamma^{v t}$.

Since the band saw only works on one log at any moment, and the production process is continuous without interruption, the minimum coefficient of utilization in timber processing is $\delta_{k}$, so $V T_{k}^{M i n}=\delta_{k} \cdot V T_{k}$. The timber mill 
manufactures boards based on clients' orders with the goal of maximizing output with minimum logs and penalty cost.

\section{Robust optimization model}

When defective logs comes out in timber processing, they must be discarded. Based on the need to maximize board output per log, the timber mill sorts raw material logs into groups for processing, which changes the volume. In this paper, we use $B \& S$ robust model to control the volume variation of timber in processing. The meanings of the symbols in this model are as follow:

$x_{k i}$ : Take 1 values to express $i$ board send to $k \log$ in the manufacture plan, if not take 0 values;

$\widehat{v t}_{k}$ : The maximum variation of volume of timber of log $k$ for manufacture, $V T_{k} \in\left[V T_{k}^{M a x}-\widehat{v t}_{k}, V T_{k}^{M a x}\right]$;

$J_{k}$ : The index assemblage of all logs with variation of volume of timber in manufacture period, $J_{k}=\left\{k \mid \widehat{v t}_{k}>0, k=1, \ldots, m\right\}$;

$\Gamma_{k}$ : Conservative horizontal of parameters, robust horizontal of $\log k, \Gamma_{k} \in\left[0,\left|\Gamma_{k}\right|\right]$;

$S_{k}$ : Sub-aggregate of $\Gamma_{k}$;

$\left\{t_{i}\right\}$ : Sub-aggregate of $S_{k}, S_{k} \cup\left\{t_{i}\right\}=J_{k}, \quad S_{k} \cap\left\{t_{i}\right\}$ $\neq \phi$;

$\left|J_{k}\right|$ : The quantity of slabs in assemblage $J_{k}$;

$\left|S_{k}\right|$ : The quantity of slabs in assemblage $S_{k}$.

The available volume of timber affected by defective quality varied. The maximum variation value is $V T_{k}^{M a x}-V T_{k}^{M i n}$. When $\Gamma_{k}=0$, it means that there is no variation in raw material logs. When $\Gamma_{k}=J_{k}$, it means that all the raw material logs are defective. The conservatism of lumber operation is the highest value. If the variation of volume of raw material $\operatorname{logs}$ is $\Gamma_{k}$, the number of unchanged volume of raw material $\operatorname{logs}$ is $\left|J_{k}\right|-\Gamma_{k}$, formula of robust as example (3):

$C_{j \in S_{0}}^{T}+\max _{\left\{S_{k} \cup\left\{t_{k}\right\}\left|S_{k} \subseteq J_{k},\right| S_{k} \mid \leq \Gamma_{k}, t_{k} \in J_{k} ¥ S_{k}\right\}}\left\{\sum_{i \in S_{k}} \widehat{V T}_{k}+\left(\Gamma_{k}-\Gamma_{k}\right) \widehat{V T}_{k}\right\}$

The relationship between board volume and standard log volume in timber processing is as example (4):

$\sum_{k=1}^{m} \sum_{i=1}^{n} v t_{i} x_{k i} \leq V T_{k}$

Available volume for manufacture formula of robust is as example (5):

$$
\begin{aligned}
& \sum_{k=1}^{m} \sum_{i=1}^{n} v t_{i} x_{k i} \leq V T_{k}-\underset{\left\{S_{k} \cup\left\{t_{k}\right\}\left|S_{k} \subseteq J_{k},\right| S_{k} \mid \leq \Gamma_{k}, t_{k} \in J_{k} ¥ S_{k}\right\}}{ } \\
& \quad \times\left\{\sum_{k \in S_{k}} \widehat{V T}_{k}+\left(\Gamma_{k}-\Gamma_{k}\right) \widehat{V T}_{k}\right\}
\end{aligned}
$$

Combine object function and linear form of robust formula, so the robust optimization model is:

$$
\begin{aligned}
& \operatorname{Min} Z=\sum_{k=1}^{m} \sum_{i=1}^{n} c_{k i}^{u} x_{k i}+\sum_{k=1}^{m} \sum_{i=1}^{n} c_{k i}^{w} x_{k i} \\
& \quad+\sum_{k=1}^{m} \sum_{i=1}^{n} c_{k i}^{v t} x_{k i} \\
& \text { s.t }\left\{\begin{array}{l}
\sum_{k=1}^{m} x_{k i}=1 \\
\sum_{k=1}^{m} \sum_{i=1}^{n} v t_{i} x_{k i} \leq V T_{k}-\alpha_{k} \Gamma_{k}-\sum_{i} \sum_{k} \rho_{\mathrm{k}} \widehat{V T} T_{k} \\
\sum_{i=1}^{\mathrm{n}} \sum_{i=1}^{n} u_{i} w_{i} l_{0}=v t_{i} \\
m=\left[V / V T_{k}\right] \\
\alpha_{k}+\rho_{k} \geq \widehat{V T}_{k} \beta_{0} \\
\alpha_{k}, \rho_{k}, \beta_{0} \geq 0 \\
v t_{i}, u_{i}, w_{i}, l_{0}, V T_{k} \geq 0
\end{array}\right.
\end{aligned}
$$

In object function (6), $\sum_{k=1}^{m} \sum_{i=1}^{n} c_{k i}^{u} x_{k i}$ is the thickness error of boards in timber processing. The second part $\sum_{k=1}^{m} \sum_{i=1}^{n} c_{k i}^{w} x_{k i}$ is the width error; the third part $\sum_{k=1}^{m} \sum_{i=1}^{n} c_{k i}^{v t} x_{k i}$ is log volume error. The first part of constraint condition (6) expresses that each slab only maps one log; the second part expresses that volume of board output is no greater than the available volume of each log; the third part defines the volume of boards; the fourth part is the quantity of logs used for manufacture; other parts are the value constraint of basic parameters.

\section{Algorithm for solution}

For the volume variation robust optimization model in timber processing, based on the strategy of sorting boards into groups by thickness which is written by Zanjani (2010), using the highly efficient search algorithm where data is limited (Liu and Lin 2005). Solving involves trying to figure out the best mapping relationship between boards and logs. Algorithm design was as follows (Varas et al. 2014; Maturana et al. 2009):

Step 1 Order and number the slabs according to thickness $u_{i}$, mark them with $\left\{P_{j}\right\}$, total get I groups, $j=\{j \mid 1 \ldots I\}$;

Step 2 Calculate minimum volume of $\operatorname{logs} m_{M i n}$ and maximum volume of logs $m_{M a x}$, sending each group raw material $\operatorname{logs} l_{j}$; and record the mapping between slabs and $\operatorname{logs}$ using $0-1$ matrix $N_{k i}$; calculate probability matrix $P_{k i}$ producing boards from $\operatorname{logs}$ by matrix $N_{k i}$, and $P_{k i}=\left[\sum_{k=0}^{k-1} p_{k i}, \sum_{k=0}^{k} p_{k i}\right], P_{0 i}=0$;

Step 3 Get original solution matrix $H_{g}^{0}$ by comparing with random number sequence and probability matrix; Step 4 Estimate the relationship between volume of slabs and available volume of logs. Calculate object function value $Z_{g}^{0}$ and slabs penalty $\operatorname{cost} c_{i}^{0}$ of $H_{g}^{0}$. Replace the maximum penalty cost of slabs with the minimum 
penalty cost of slabs. Estimate the relationship between the volume of slabs and logs and calculate object function value $Z_{g}^{n}$;

Step 5 Estimate the relationship between $Z_{g}^{n}$ and $Z_{g}^{n-1}$ until iteration finished and get the best solution $Z_{g}^{*}$.

\section{Optimization of timber volume variation}

\section{Manufacture data}

In this paper, using small diameter oak with a diameter of $20 \mathrm{~cm}$, and length of $2 \mathrm{~m}$ as the raw material. Based on the purchase order, there are 57 boards to produce, divided into different groups by thickness. The requirements for different size slabs is in Table 1.

According to the parameters in robust optimization model, take $\gamma^{u}=1.0, \gamma_{+}^{w}=0.35, \gamma_{-}^{w}=1.4, \gamma^{v t}=1500$, $\delta_{k}=0.50, V T_{k}=0.0720$. The maximum unit of thickness penalty is $5 \mathrm{~mm}$, and the minimum unit of thickness penalty is $2 \mathrm{~mm}$.

\section{Evaluating indicator}

For the volume variation of the robust optimization model in this paper, we evaluated timber processing with the sawn timber volume per log, the by-product volume per log and the total output of boards. We compared and analyzed traditional timber-processing models and the robust optimization model to get a result by using an evaluation indicator.

The sawn timber volume of per $\log (\%)$ :

$\eta_{0}=\left(\sum_{i=1}^{n} v t x_{k i}\right) / V T_{k}^{\prime}$

The total output of boards $(\%)$ :

$\eta_{1}=\left(\sum_{i=1}^{n} v t x_{k i}\right) /\left(V T_{k} \cdot m\right)$

Table 1 Requirements for different size slabs

\begin{tabular}{llcc}
\hline $\begin{array}{l}\text { Group } \\
\text { no. }\end{array}$ & $\begin{array}{l}\text { Thickness of } \\
\text { boards }(\mathrm{mm})\end{array}$ & $\begin{array}{l}\text { Width of boards } \\
(\mathrm{mm})\end{array}$ & $\begin{array}{l}\text { Quantity of } \\
\text { boards }\end{array}$ \\
\hline 1 & 30 & 28 & 8 \\
& & 136 & 6 \\
& & 172 & 6 \\
2 & 35 & 50 & 12 \\
& & 148 & 14 \\
& & 178 & 6 \\
3 & 40 & 164 & 2 \\
& & & 3 \\
\hline
\end{tabular}

The by-product volume of per $\log (\%)$ :

$F=\left(1-\eta_{0}\right) \times V T+v t^{\prime}$

where, $V T_{k}^{\prime}$ expresses the volume of logs less the defective quality portion, and $v t^{\prime}$ expresses the net volume of boards.

\section{Results}

We used MATLAB to seek a solution to the robust-optimization model with controllable variation in the volume of timber. In order to quantify cutting pattern changes in the robust optimization model when it was controlling volume variation of timber, we chose No. 2 log with defective quality for comparison and analysis. The result is expressed in Tables 2 and 3. The defects in these tables were cutting sawn timber defects, and the grade of boards was estimated by standard subdivision of boards.

We compared indexes in timber processing processes according to different model results and optimize the

Table 2 Traditional timber processing model result

\begin{tabular}{rrrrlll}
\hline$k$ & $n$ & $u_{i}$ & \multicolumn{1}{l}{$w_{i}$} & \multicolumn{1}{l}{$v t_{i}$} & Quality defect & $\begin{array}{l}\text { Level } \\
\text { of } \\
\text { slabs }\end{array}$ \\
\hline 2 & 7 & 30 & 28 & 0.00168 & Knot $\emptyset=15$ & 3 \\
& 8 & 30 & 136 & 0.00816 & No knot & 1 \\
& 9 & 30 & 172 & 0.01032 & & 1 \\
10 & 30 & 172 & 0.01032 & & 1 \\
& 11 & 30 & 136 & 0.00816 & & 1 \\
12 & 30 & 28 & 0.00168 & & 1
\end{tabular}

$k$ Stands for the log number; $n$ stands for the board number; $u_{i}$ stands for the thickness of board $i(\mathrm{~mm}) ; w_{i}$ stands for width of board $i(\mathrm{~mm})$; $v t_{i}$ stands for the volume of board $i\left(\mathrm{~m}^{3}\right)$

Table 3 Robust optimization model result

\begin{tabular}{|c|c|c|c|c|c|c|}
\hline$k$ & $n$ & $s$ & $w_{i}$ & $v t_{i}$ & Quality defect & $\begin{array}{l}\text { Level } \\
\text { of } \\
\text { slabs }\end{array}$ \\
\hline \multirow[t]{9}{*}{2} & 7 & 30 & 28 & 0.00168 & \multirow[t]{9}{*}{ No knot } & 1 \\
\hline & 8 & 30 & 46 & 0.00276 & & 1 \\
\hline & 9 & 30 & 46 & 0.00276 & & 1 \\
\hline & 10 & 30 & 46 & 0.00276 & & 1 \\
\hline & 11 & 30 & 46 & 0.00276 & & 1 \\
\hline & 12 & 30 & 46 & 0.00276 & & 1 \\
\hline & 13 & 30 & 136 & 0.00816 & & 1 \\
\hline & 14 & 30 & 172 & 0.01032 & & 1 \\
\hline & 15 & 30 & 172 & 0.01032 & & 1 \\
\hline
\end{tabular}

$k$ Stands for the log number; $n$ stands for the board number; $u_{i}$ stands for the thickness of board $i(\mathrm{~mm}) ; w_{i}$ stands for width of board $i(\mathrm{~mm})$; $v t_{i}$ stands for the volume of board $i\left(\mathrm{~m}^{3}\right)$ 
Table 4 Indexes of variation problem of lumber before and after optimization

\begin{tabular}{|c|c|c|c|c|c|c|c|c|c|c|}
\hline \multirow[t]{2}{*}{$k$} & \multicolumn{5}{|c|}{ Traditional lumber model } & \multicolumn{5}{|c|}{ Robust optimization model } \\
\hline & $n$ & $\eta_{0}(\%)$ & $\eta_{1}(\%)$ & $F$ & $Z$ & $n$ & $\eta_{0}$ & $\eta_{1}(\%)$ & $F$ & $Z$ \\
\hline 1 & 6 & 56.00 & 56.00 & 0.03168 & 47.5 & 6 & 56.00 & 56.00 & 0.03168 & 47.5 \\
\hline 2 & 6 & 56.35 & 54.83 & 0.03291 & 49.4 & 9 & 62.03 & 58.82 & 0.02717 & 79.8 \\
\hline 3 & 6 & 57.60 & 50.48 & 0.03952 & 59.3 & 7 & 61.14 & 59.03 & 0.02720 & 69.8 \\
\hline 4 & 5 & 55.81 & 51.81 & 0.03182 & 47.7 & 5 & 55.81 & 58.22 & 0.03182 & 47.7 \\
\hline 5 & 5 & 55.81 & 52.61 & 0.03182 & 47.7 & 5 & 55.81 & 57.74 & 0.03182 & 47.7 \\
\hline 6 & 5 & 56.03 & 53.14 & 0.03503 & 52.2 & 4 & 52.24 & 56.95 & 0.03425 & 64.8 \\
\hline 7 & 5 & 56.16 & 52.83 & 0.03487 & 52.3 & 3 & 46.62 & 55.44 & 0.03819 & 59.0 \\
\hline 8 & 5 & 55.81 & 53.20 & 0.03182 & 47.7 & 5 & 55.81 & 55.48 & 0.03182 & 47.7 \\
\hline 9 & 5 & 55.81 & 53.50 & 0.03182 & 47.7 & 5 & 55.81 & 55.52 & 0.03182 & 47.7 \\
\hline 10 & 4 & 55.56 & 53.70 & 0.03200 & 48.0 & 4 & 55.56 & 55.52 & 0.03200 & 48.0 \\
\hline 11 & 5 & 58.44 & 54.13 & 0.02992 & 65.3 & 4 & 55.22 & 55.49 & 0.03224 & 91.0 \\
\hline 12 & 5 & 54.25 & 51.76 & 0.04042 & 157.41 & - & - & - & - & - \\
\hline Total & 62 & - & 51.76 & 0.40363 & 722.2 & 57 & - & 55.49 & 0.35001 & 650.7 \\
\hline
\end{tabular}

Notes: $k$ stands for the number of logs; $n$ stands for the number of boards; $\eta_{0}$ stands for the recovery ratio of sawn timber; $\eta_{1}$ stands for the recovery ratio of board; $F$ stands for the volume of by-product; $Z$ stands for the penalty cost of manufacturing effects of the robust optimization model in controlling the variation problem of timber. Indexes of different models are shown in Table 4.

In Table 4, we can determine that the variation ratio is somewhat greater for the sawn timber volume of per log in the robust optimization model than the traditional timber processing model. It shows that the robust optimization model is controlling the variation problem of lumber by sacrificing the smoothness of sawmilling. There are 57 boards in the robust optimization model for timber processing, using $11 \operatorname{logs}$, with total by-product volume reduction from 0.40363 to $0.35001 \mathrm{~m}^{3}$, an improvement of $0.05362 \mathrm{~m}^{3}$. The manufacturing cost penalty was reduced from 722.2 to 650.7 Yuan (CNY), 71.5 Yuan (CNY) better than before. The total output of boards raises from 51.76 to 55.49 , a $3.73 \%$ improvement.

\section{Conclusion}

We evaluated the volume variation of raw material logs in timber processing and set up a robust optimization model. We developed a solution with the robust optimization approach and found the relationship between boards and raw material logs in timber processing. We optimized the results, showing that robust optimization can control the volume variation in timber processing, reduce by-product volume, and lower the manufacturing cost penalty. Sawmill enterprises using these research results are able to easily determine the relationship between the requirement of the robust model and timber processing and choose a flexible method of timber processing, which could lower cost. We are able to supply theoretical evidence and references to solve uncertain parameter controlling problems for similar enterprises or similar processes in manufacturing. With the natural forest closed for commercial felling, a rational use of the robust optimization approach can improve the output of boards and maximize the log usage, which will help to protect forest resources

Open Access This article is distributed under the terms of the Creative Commons Attribution 4.0 International License (http://crea tivecommons.org/licenses/by/4.0/), which permits unrestricted use, distribution, and reproduction in any medium, provided you give appropriate credit to the original author(s) and the source, provide a link to the Creative Commons license, and indicate if changes were made.

\section{References}

Alem DJ, Morabito R (2012) Production planning in furniture settings via robust optimization. Comput Oper Res 39(2):139-150

Alvarez PP, Vera JR (2014) Application of robust optimization to the sawmill planning problem. Ann Oper Res 219(1):457-475

Ben-Tal A, Nemirovski A (2000) Robust solutions of Linear Programming problems contaminated with uncertain data. Math Program 88(3):411-424

Bental A, Goryashko A, Guslitzer E, Nemirovski A (1999) Robust solutions to uncertain linear programs. OR Lett 25(1):1-13

Bertsimas D, Sim M (2003) Robust discrete optimization and network flows. Math Program 98(1):49-71

Bertsimas D, Sim M (2004) Robust discrete optimization and downside risk measures. National University of Singapore, working paper 
Bertsimas D, Sim M (2004b) The price of robustness. Oper Res $52(1): 35-53$

Leung SCH, Chan SSW (2009) A goal programming model for aggregate production planning with resource utilization constraint. Comput Ind Eng 56(3):1053-1064

Liu SC, Lin CC (2005) A heuristic method for the combined location routing and inventory problem. Int $\mathrm{J}$ Adv Manuf Technol 26(4):372-381

Maturana S, Pizani E, Vera J (2009) Scheduling production for a sawmill: a comparison of a mathematical model versus a heuristic. Comput Ind Eng 59(4):667-674
Soyster AL (1973) Convex programming with set-inclusive constraints and applications to inexact linear programming. Oper Res 21(5):1154-1157

Varas M, Maturana S, Pascual R, Vargas I, Vera J (2014) Scheduling production for a sawmill: a robust optimization approach. Int J Prod Econ 150(6):37-51

Zanjani MK, Kadi DA, Nourelfath M (2010) Robust production planning in a manufacturing environment with random yield: a case in sawmill production planning. Eur J Oper Res 201(3):882-891 